\title{
The Effect of Mass, Depth, and Properties of the Soil Below the Raft Foundation on the Seismic Performance of R.C. Plane Frames
}

\author{
Jamal Ahmad Alomari \\ Civil Engineering Department, \\ Al-Ahliyya Amman University, \\ Amman, Jordan \\ j.alomari@ammanu.edu.jo
}

\begin{abstract}
Soil structure interaction (SSI) has been the subject of numerous studies. The foundation soil has a definite effect on the performance of structures during seismic excitation. Recent studies show that the effect of soil-structure interaction SSI may be detrimental to the structure during seismic excitation. In this study, the effect of consideration of the soil below foundation and its depth, and the soil modulus of elasticity on the response of structures is investigated. The number of mode shapes considered has an effect on the accuracy of the values of structure response. A structural model consisting of an 8-story reinforced concrete frame resting on raft foundation, and including the soil below the raft is analyzed. The frame is analyzed using SAP2000 software, and time history and modal analysis are carried out with varying values of both soil depth and soil modulus of elasticity. The soil below the foundation is connected to the raft elements by gap links. Gap element links are compression-only members with appropriate stiffness, which are active only in compression. Modal analysis results show that the periods of vibration decrease as the modulus of elasticity of the soil increases. Periods of vibration of the frame without the soil mass consideration are less than those when the soil mass below the raft is considered, and they increase with increased depth of foundation to a certain limit. The structures response in the form of columns shear forces and story displacements are also evaluated under the variable parameters considered.
\end{abstract}

Keywords-SSI; soil mass depth; number of mode shapes; seismic; period of vibration; soil modulus of elasticity; column shear force; story displacement; gap link

\section{INTRODUCTION}

The effect of soil-structure interaction on the performance of structures during seismic excitation has been the subject of extensive research, mostly theoretical rather than experimental due to the self-evident difficulty of experimental work. It is well known that the soil mass below the structure foundation and the structure have a mutual effect on each other during earthquake excitation. This is known as soil-structure interaction (SSI). The soil in general has non-linear properties both in geometric and material behavior. However it is considered as consisting of layered linear shell elements in this analysis. Its flexibility and deformation during earthquakes have an immediate and sometimes detrimental effect on the structure's behavior. The flexibility of the soil mass may amplify ground shaking and change the structure response dramatically. Design practice usually treats the structures as fixed at the base and ignores the flexibility and settlement of the soil mass below. Moreover, the number of mode shapes considered in the seismic analysis affects the accuracy of the values of the structure response, such as story displacement, and column shear forces. The effect of higher modes of vibration on the structure response using fixed-base structures without consideration of the soil mass below has been studied in depth. This paper considers the effect of consideration of higher modes on the structure response during time history analysis with due consideration of the SSI. The codes of practice usually specify a minimum number of mode shapes to be considered to arrive to a certain level of accuracy. In fact, this minimum is different for different parameters such as the story displacement and column shear forces. This paper tries to show the effect of the depth of soil mass, and its properties on the structure response during seismic excitation, as well as the minimum number of modes needed to arrive at a certain level of accuracy for the structure responses while including SSI.

\section{LITERATURE REVIEW}

Authors in [1] studied the local site effects excluding SSI for midrise moment resisting frames of 5, 10, and 15 story heights with 2 soil types having shear wave velocity less than $600 \mathrm{~m} / \mathrm{s}$. They concluded that excluding the fact that the SSI cannot adequately guarantee the structure safety for structures higher than 5 stories resting on soft soils. Authors in [2] carried out theoretical research on multi-floor frames with various parameters of the soil below foundation and number of stories to show the effect of SSI effects on the dynamic properties of the frames. They compared the results with the fixed -base structures. They research concluded that as the soil stiffness increases, the fundamental period for the structural model decreases, and that the fundamental period for the structural model is not only a function of building height but also a function of SSI. Authors in [3] carried out a theoretical study on a 8-story reinforced concrete frame on raft foundation 
including the soil mass below to study the effect of SSI on the settlement of the structure, bearing pressure, and bending moments in the raft and stresses on slabs. Authors in [4] analyzed a 15 -story R. C. moment resisting frames founded on soft soils, with bedrock depths of 10, 20, and 30 meters. The performance of the fixed base frame in the form of the story drift was compared with that of the frame with soil-structure interaction. They concluded that increasing the bedrock depth increases lateral deflections and inter-story drifts of the structures. Authors in [5] considered 3 types of buildings for dynamic analysis. These were a shear building with constant columns stiffness, a shear building with variable columns stiffness, and a flexural building, without considering SSI. Their analysis aimed at finding the number of mode shapes considered to arrive at $5 \%$ and $10 \%$ levels of accuracy for the values of base shear and top story shear forces. They concluded to simple formulas that keep the relative errors of the building response within the specified percentages. Authors in [6] studied a finite element model of a 2-story plane frames with soil-structure interaction under dynamic loading considering a wide range of shear wave velocity of the soil. They concluded that SSI influences all modes of the structure and particularly the vertical modes. They also concluded that dynamic SSI generally leads to lower eigen frequencies for the coupled structure.

\section{STRUCTURE DESCRIPTION AND METHOD OF ANALYSIS}

The reinforced concrete plane frame shown in Figure 1 consists of 8 floors. The beams are $1.0 \mathrm{~m} \times 0.3 \mathrm{~m}$ and the columns are $0.5 \mathrm{~m} \times 0.5 \mathrm{~m}$. The frame rests on reinforced concrete raft foundation of $0.7 \mathrm{~m}$ thickness, modeled as beam elements with dimensions of $3.96 \mathrm{~m} \times 0.7 \mathrm{~m}$. The raft beam elements are further divided into $0.66 \mathrm{~m}$ long beam elements. The concrete has a compressive strength of $27.57 \mathrm{MPa}$. The soil below the raft is modeled as layered shell elements, with $2.5 \mathrm{~m}$ depth of each layer, and with varying modulus of elasticity. Soil shell elements are connected to the raft elements via compression-only gap element links. These are active in compression only otherwise they have no effect on the structure. They are assigned little stiffness values. The soil boundary joints are considered fixed. As such, the bedrock layer is realized at the bottom and at the sides of the soil layers. The depth of the soil mass varies from $7.5 \mathrm{~m}$ to $30 \mathrm{~m}$. The soil properties in the form of its modulus of elasticity are varied from a value of $60 \mathrm{MPa}$ to a value of $300 \mathrm{MPa}$. This range of values is typical for soils ranging from dense sands to hard rock
[7]. The frame described is subjected to typical gravity loads. Linear time history analysis using the modal solution type of the frame, foundation and soil below is carried out. The N-S El Centro time history acceleration is used with a scale factor of 0.1 .

\section{RESULTS AND DISCUSSION}

The first 10 periods of vibration of the frame against the soil modulus of elasticity are shown in Table I. It is observed that the periods decrease as the modulus of elasticity of the foundation soil increases. This observation is in agreement with the findings of $[3,8]$. More runs of SAP2000 [10] were carried out to investigate the effect of varying number of modes on the accuracy of the frame response of story displacement, and column shear forces. For this purpose, the frame is analyzed using time history acceleration of the N-S component of El Centro record scaled to 0.1 using the modal solution type. The soil modulus of elasticity is considered $100,000 \mathrm{MPa}$ for all runs for this purpose. Table II shows the displacements of some joints of the structure using different number of modes, and Table III shows the shear forces in selected columns of the frame with varying number of modes.

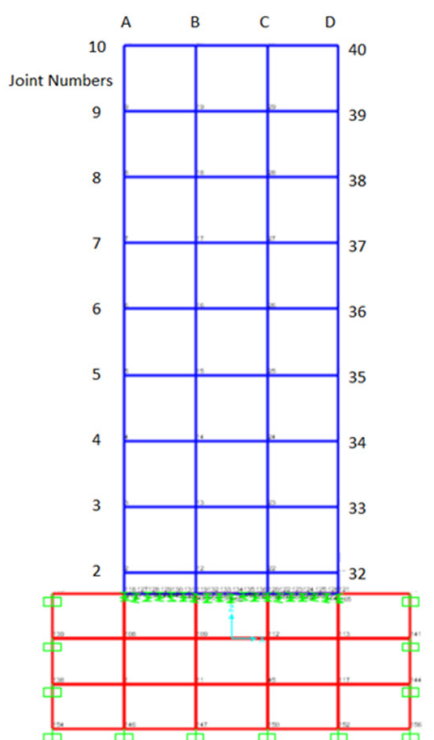

Fig. 1. Reinforced concrete plane frame and soil below the raft foundation of $7.5 \mathrm{~m}$ depth

TABLE I. VIBRATION PERIODS VS SOIL MODULUS OF ELASTICITY

\begin{tabular}{|c|c|c|c|c|c|c|c|c|}
\hline $\begin{array}{c}E \text { of soil (MPa) } \\
\text { Period No }\end{array}$ & 60 & 80 & 100 & 120 & 140 & 200 & 260 & 300 \\
\hline 1 & 0.618159 & 0.589168 & 0.571294 & 0.559174 & 0.550416 & 0.534432 & 0.525701 & 0.52179 \\
\hline 2 & 0.194967 & 0.17763 & 0.17113 & 0.168536 & 0.167237 & 0.165596 & 0.164947 & 0.164694 \\
\hline 3 & 0.157704 & 0.149354 & 0.138538 & 0.128471 & 0.120041 & 0.103119 & 0.097416 & 0.096526 \\
\hline 4 & 0.131757 & 0.119397 & 0.110484 & 0.10405 & 0.099759 & 0.094192 & 0.087192 & 0.081987 \\
\hline 5 & 0.099767 & 0.094051 & 0.092901 & 0.091626 & 0.089659 & 0.080809 & 0.073206 & 0.069746 \\
\hline 6 & 0.093854 & 0.085042 & 0.076805 & 0.071145 & 0.068919 & 0.068237 & 0.067867 & 0.067174 \\
\hline 7 & 0.086504 & 0.075461 & 0.067935 & 0.064997 & 0.063532 & 0.054391 & 0.049573 & 0.050197 \\
\hline 8 & 0.074895 & 0.066347 & 0.061014 & 0.059412 & 0.056321 & 0.048 & 0.045486 & 0.044027 \\
\hline 9 & 0.062798 & 0.05976 & 0.055354 & 0.051622 & 0.04826 & 0.041115 & 0.03813 & 0.036902 \\
\hline 10 & 0.037754 & 0.03641 & 0.034435 & 0.032522 & 0.030664 & 0.026159 & 0.031023 & 0.031177 \\
\hline
\end{tabular}


TABLE II. JOINT DISPLACEMENT AT SELECTED JOINTS

\begin{tabular}{|c|c|c|c|c|c|c|c|c|c|}
\hline No. of modes & $\mathbf{1}$ & $\mathbf{2}$ & $\mathbf{3}$ & $\mathbf{5}$ & $\mathbf{7}$ & $\mathbf{1 0}$ & $\mathbf{2 0}$ & $\mathbf{3 0}$ & $\mathbf{5 0}$ \\
\hline Joint 33 & 0.0300 & 0.038 & 0.0312 & 0.0363 & 0.0374 & 0.03815 & 0.0382 & 0.0382 & 0.0382 \\
\hline Joint 37 & 0.0940 & 0.0164 & 0.162 & 0.155 & 0.151 & 0.1458 & 0.155 & 0.155 & 0.155 \\
\hline Joint 40 & 0.0121 & 0.0224 & 0.235 & 0.242 & 0.244 & 0.2405 & 0.240 & 0.240 & 0.240 \\
\hline
\end{tabular}

TABLE III. SHEAR FORCE IN SELECTED COLUMNS

\begin{tabular}{|c|c|c|c|c|c|c|c|c|c|}
\hline Number of modes & $\mathbf{1}$ & $\mathbf{2}$ & $\mathbf{3}$ & $\mathbf{5}$ & $\mathbf{7}$ & $\mathbf{1 0}$ & $\mathbf{2 0}$ & $\mathbf{3 0}$ & $\mathbf{5 0}$ \\
\hline Column 29 joints 32-33 & 314.2 & 488.6 & 364.2 & 400.00 & 354.8 & 394.4 & 394.4 & 394.4 & 394.4 \\
\hline Column 33 joints 36-37 & 138.4 & 305.3 & 377.4 & 347.3 & 182.5 & 199.8 & 199.8 & 199.8 & 199.8 \\
\hline Column 36 joints 39-40 & 19.7 & -18.7 & 86.4 & 136.1 & 176.3 & 110.1 & 110.1 & 110.1 & 110.1 \\
\hline
\end{tabular}

The "exact" response of the frame can be considered as the one using all modes of vibration. It is possible to calculate the relative error in the response by taking the difference between the "exact" value and the value including a reduced number of mode shapes. From Tables II and III, it is seen that including 20 mode shapes in the calculations of the displacements and column shear forces produced zero percent errors. However, usually, it is sufficient to include few of the mode shapes in the calculations depending on the desired accuracy. The level of accuracy depends on the element of the structure under consideration in addition to two other factors, namely the modal contribution factor and the spectral coordinate [9]. From Table II, it is observed that including 5 modes in the calculations of the lateral displacements produces errors of $-5 \%, 0 \%$, and $+0.83 \%$ for joints 33,37 , and 40 respectively. As for the shear forces in columns, including 7 mode shapes in the calculations produces errors of $-10 \%,-8.7 \%$, and $+60.1 \%$. It is clear that the shear forces in columns require more mode shapes than the displacements for acquiring the same accuracy. The height of the member or joint under consideration above the base of the structure is another factor affecting the accuracy of the response. The error percentage in the top floor displacement is less than in the lower joints displacements for the same number of modes. This is not the same for shear forces in columns where the top floor columns require more modes to be included than the lower columns for the same accuracy. These findings are in agreement with the findings of $[3,5]$.

\section{EFFECT OF INCLUDING THE SOIL MASS BELOW THE RAFT AND THE SOIL MASS DEPTH}

To investigate the effect of including the soil mass below the raft, and the effect of its depth on the period of vibration, the same frame is analyzed first without the soil mass, i.e. bare frame, and then with soil depths of $7.5 \mathrm{~m}, 15.0 \mathrm{~m}, 22.5 \mathrm{~m}$, and $30.0 \mathrm{~m}$ (Figure 2). Table IV shows the periods of vibration of the bare frame, and with the above mentioned soil depths. Comparing the periods of vibration of the bare frame with that of the structure with $7.5 \mathrm{~m}$ deep soil mass, it is observed that there is an increase of around $15 \%$ in its value. More depth of the soil mass increases the period length but to a limited value. This also depends on the value of the soil modulus of elasticity. In other words, soil flexibility imparts flexibility to the structure, and this effect is more pronounced with soft soils having a shear wave velocity of $600 \mathrm{~m} / \mathrm{s}$ or less [1].

\section{MODE SHAPES}

For completeness, Figure 3 shows some of the mode shapes of the structure with a soil depth of $30 \mathrm{~m}$. It is obvious from the deformation of the soil below the raft foundation, e.g. mode shape number 5 , how the structure performance is affected
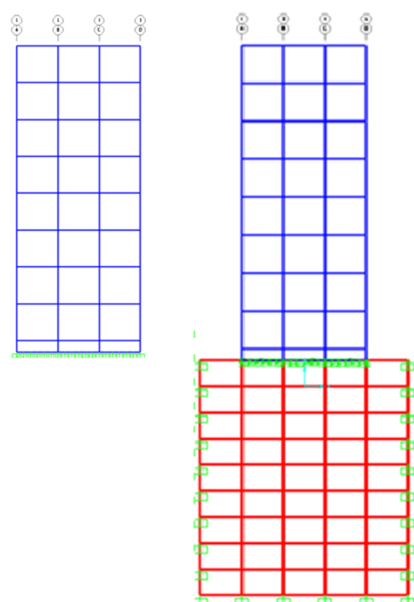

(a)

(b)

Fig. 2. (a) The plane frame without the soil mass below the raft foundation, and (b) the frame with soil depth of $22.5 \mathrm{~m}$

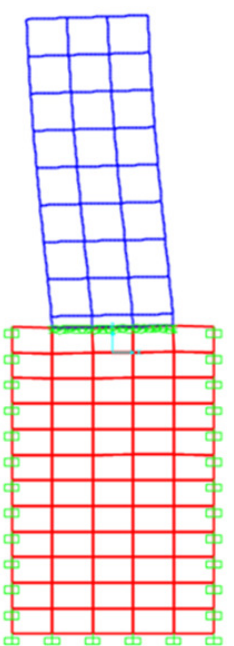

(a)

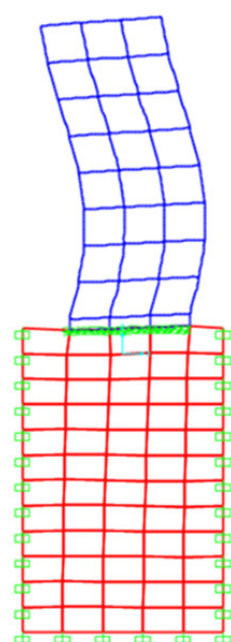

(b)

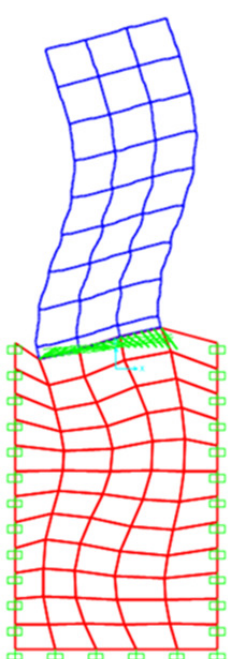

(c)
Fig. 3. Mode shapes (a) 1, (b) 2, and (c) 5 
TABLE IV. FIRST 10 PERIODS OF VIBRATION OF THE FRAME SHOWN IN FIGURE 1 WITH VARYING SOIL DEPTH BELOW THE FOUNDATION

\begin{tabular}{|c|c|c|c|c|c|}
\hline \multirow{2}{*}{$\begin{array}{c}\text { Period } \\
\text { No. }\end{array}$} & \multicolumn{5}{|c|}{ Period (s) } \\
\hline & Without soil below the raft & With soil depth $=7.5 \mathrm{~m}^{*}$ & With soil depth $=15 \mathrm{~m} *$ & With soil depth $=22.5 \mathrm{~m}^{*}$ & With soil depth $=30 \mathrm{~m}^{*}$ \\
\hline 1 & 0.495405 & 0.571294 & 0.576505 & 0.576701 & 0.576707 \\
\hline 2 & 0.163307 & 0.17113 & 0.177173 & 0.179174 & 0.179683 \\
\hline 3 & 0.094817 & 0.138538 & 0.154888 & 0.159159 & 0.162008 \\
\hline 4 & 0.068374 & 0.110484 & 0.131925 & 0.145083 & 0.1533 \\
\hline 5 & 0.054196 & 0.092901 & 0.110795 & 0.125378 & 0.133296 \\
\hline 6 & 0.046517 & 0.076805 & 0.097386 & 0.116624 & 0.109966 \\
\hline 7 & 0.042821 & 0.067935 & 0.088106 & 0.094202 & 0.095989 \\
\hline 8 & 0.039289 & 0.061014 & 0.068064 & 0.078491 & 0.082779 \\
\hline 9 & 0.014975 & 0.055354 & 0.061655 & 0.065283 & 0.06561 \\
\hline 10 & 0.010402 & 0.034435 & 0.04612 & 0.053339 & 0.055881 \\
\hline
\end{tabular}

$* E=100000 \mathrm{MPa}$

\section{CONCLUSION}

Based on the findings of this study, the following conclusions can be drawn:

- Consideration of the soil mass below the raft foundation of R. C. framed structures increases the length of periods of vibration.

- Increasing the depth of the soil mass below the raft foundation increases the periods of vibration up to a limited value depending on the soil modulus of elasticity $E$. For the considered case where $E=100,000 \mathrm{MPa}$, soil mass depth of $10 \mathrm{~m}$ is enough to arrive at the maximum effect of the soil mass on the values of periods of vibration, beyond which periods remain constant.

- The type of soil below foundation, measured by its modulus of elasticity, has an increasing effect on the structure response as its modulus of elasticity is decreasing. Soft soils with low modulus of elasticity impart more flexibility to the structures than stiff soils

- It was found that shear forces in columns require consideration of more mode shapes than story displacements in order to arrive at the same level of accuracy as compared to the "exact" value, which is the one including the total number of mode shapes.

- The shear force in higher floor columns requires more mode shapes than in the lower columns to be included in the solution to arrive at the same level of accuracy.

- The displacement at lower floors requires more mode shapes to be included in the solution to arrive at the same level of accuracy, and that is opposite to the case of shear force in columns.

- The seismic demand of the structure should take account of the soil mass beneath structures including its properties and depth in order to avoid underestimation of the base shear calculated according to the equations stipulated in the codes of practice.

\section{REFERENCES}

[1] B. Fatahi, S. H. R. Tabatabaiefar, B. Samali, "Soil-structure interaction vs site effect for seismic design of tall buildings on soft soil", Geomechanics and Engineering, Vol. 6, No. 3, pp. 293-320, 2014
[2] S. E. Abdel Raheem, M. M. Ahmed, T. M. A. Alazrak, "Evaluation of soil-foundation-structure interaction effects on seismic response demands of multi-story MRF buildings on raft foundations", International Journal of Advanced Structural Engineering, Vol. 7, No. 1, pp. 11-30, 2015

[3] B. Moczar, Z. Polgar, A. Mahler, "A comparative study of soil-structure interaction in the case of frame structures with raft foundation", Materials and Geoenvironment, Vol. 63, No. 1, pp. 1-8, 2016

[4] B. Fatahi, S. H. Reza Tabatabaifar, A. S. Hokmabadi, B. Samali, "Significance of Bedrock Depth in Dynamic Soil-Structure Interaction Analysis for Moment Resisting Frames", 2nd International Conference On Performance-Based Design In Earthquake Geotechnical Engineering, Taormina, Italy, May 28-30, 2012

[5] O. A. Lopez, M. Cruz, "Number of modes for the seismic design of buildings", Earthquake Engineering and Structural Dynamics, Vol. 25, No. 8, pp. 837-855, 1996

[6] M. Papadopoulos, R. Van Beeumen, S. Francois, G. Degrande, G. Lombaert, "Computing the modal characteristics of structures considering soil-structure interaction effects", Procedia Engineering, Vol. 199, pp. 2414-2419, 2017

[7] R. Obrzud, A. Truty, The Hardening Soil Model -A Practical Guidebook, Zace Services Ltd, 2012

[8] S. Lamar, C. Fortoul, "Brick Masonry Effect in Vibrations of Frames", in: Proceedings of the 4th World Conference on Earthquake Engineering, Vol. 2, pp. 91-98, 1969

[9] A. K., Chopra, Dynamics of Structures Theory and Applications to Earthquake Engineering, Prentice Hall, 2017

[10] https://www.csiamerica.com/products/sap2000 